\title{
As Contribuições de Émile Durkheim para Compreender a Religião na Contemporaneidade
}

\author{
Celso Gabatz* \\ Jefferson Zeferino**
}

\begin{abstract}
RESUMO
Émile Durkheim dedicou-se à definição dos fenômenos religiosos e às doutrinas teológicas. Procurou demonstrar a relação seminal entre religião e ciência com a ajuda do conceito de representação coletiva. As transformações nas práticas religiosas são explicadas em função de fatores externos ao fenômeno religioso. As representações seriam o resultado da divisão social do trabalho e da especialização ocupacional. O problema nesta nossa abordagem tem a ver com a capacidade dos indivíduos para criar formas de moralidade que serviriam de substrato para a vida. Nossa hipótese é que mesmo com a ciência impulsionando a maioria das cosmologias que detinham as explicações acerca do mundo para fora das fronteiras da racionalidade, a sociedade tende a suscitar a comunhão das consciências que nasce do sentimento de dependência partilhada.

Palavras-chave: Émile Durkheim. Religião. Coletividade.
\end{abstract}

* Pós-Doutorando e Professor Colaborador no Programa de Pós-Graduação (Mestrado e Doutorado) da Faculdades EST, São Leopoldo, RS. Doutor em Ciências Sociais (UNISINOS). Mestre em História (UPF). Pós-Graduado em Ciência da Religião e Docência no Ensino Superior. Graduado em Sociologia (UNIJUI); Teologia (EST); Filosofia (CEUCLAR). Contato: gabatz12@hotmail.com CV: http://lattes.cnpq.br/7404950936752263

** Doutorando em Teologia pela Pontifícia Universidade Católica do Paraná, PUCPR. Editor Associado da Teoliterária: Revista Brasileira de Literaturas e Teologias. Assessor teológico do Movimento Ecumênico de Curitiba, MOVEC. Membro do grupo de pesquisa Teopatodiceia: Espiritualidade, Cultura, Práxis. Membro do Núcleo Ecumênico e de Diálogo Inter-religioso do Instituto Ciência e Fé da PUCPR. Bolsista CAPES. Contato: jefferson.zeferino@hotmail.com. CV: http://lattes.cnpq.br/3365290019359083 


\title{
ÉMILE DURKHEIM'S CONTRIBUTIONS TO UNDERSTAN- DING THE RELIGION IN CONTEMPORANEITY
}

\begin{abstract}
Émile Durkheim wrought on the definition of religious phenomena an on theological doctrines. He demonstrated the relation between religion and science through the concept of collective representation. The transformations in religious practices in modern societies would be explained by factors external to the religious phenomena. The representations would be the result of social work division and occupational specialization. The problem the text approaches is about the capacity individual have to create new forms of morality that would work as substrate for life. Our hypothesis lies on the idea that even with science propelling most of the cosmologies that try to explain the world outwards rationality borders, society tends to raise the communion of consciences that grows form shared dependence.
\end{abstract}

Keywords: Émile Durkheim. Religion. Collectivity.

\section{Introdução}

A concepção entabulada por Émile Durkheim ${ }^{1}$ acerca da religião é sublinhada por uma ideia bastante simples. Ela seria um produto social criado por indivíduos que agem e pensam de forma coletiva, interagindo e estabelecendo condições para que a vida em conjunto continue a existir. É por isso que a religião é capaz de retratar a vida pressupondo a compreensão do fenômeno religioso a partir de suas múltiplas manifestações em suas inumeráveis formas de vivência coletiva.

\footnotetext{
David Émile Durkheim (1858-1917) nasceu no seio de uma família de linhagem judia no noroeste da França. Após a morte do pai, com o auxílio de amigos, consegue ingressar na Escola Normal Superior de Paris, em 1879. Oito anos depois, em 1887, torna-se professor da primeira cátedra de sociologia instituída pela Universidade de Bordeaux. Entre 1893 e 1895 publica duas de suas importantes obras: Da Divisão do Trabalho Social (2008) e As Regras do Método Sociológico (2007). Estabelece com elas, o conceito de consciência coletiva como um sistema de crenças e sentimentos comuns que explicam as relações entre os membros de uma sociedade. Publicou ainda, em 1912, As Formas Elementares da Vida Religiosa (2000) na qual esboçou uma teoria da religião comparando a vida social e cultural das sociedades primitivas e modernas. É reverenciado como um dos principais protagonistas da sociologia moderna por ter buscado estabelecer as bases para uma sociologia como ciência independente, com um objeto, uma crítica e uma abordagem peculiar (GIDDENS, 1986).
} 
A religião, na medida em que corresponde às necessidades reais da sociedade, não deveria ser vista como algo capaz de ser eliminado, mesmo porque ela não se reduziria à esfera racional e também por desempenhar um papel estratégico na orientação das ações cotidianas. Uma espécie de referencial que os indivíduos não poderiam prescindir de forma apenas pragmática.

Acentua-se a ideia de sagrado em conexão com a coletividade e diretamente sintonizada com os indivíduos a partir de uma autoridade moral. Há uma problematização que tem a ver com os elementos fundantes da religião. Trata-se de uma perspectiva voltada para as ações na medida em que o simbolismo religioso atua com a função de reproduzir hierarquias. A pretensa descontinuidade entre as sociedades tradicionais e contemporâneas não seria, portanto, tão clara. Haveria entre elas permanências, tanto em relação às formas de classificação do mundo como também em relação aos símbolos e ritos que sublinham a vida social.

Busca-se vislumbrar, neste artigo, que as representações de mundo elaboradas pelos indivíduos tiveram uma origem religiosa e as categorias que fundamentam a compreensão contemporânea, como as noções de tempo, espaço, causas, número, foram em sua origem, elaboradas a partir de crenças religiosas. Com isso, não se diz que as doutrinas religiosas são verdadeiras em um sentido científico, mas que a principal prerrogativa da religião é a organização da existência social e que os antigos valores talvez sejam insuficientes mediante a complexidade da sociedade contemporânea.

A religião, objetivamente, não é apenas resultante de cultos a determinadas divindades, mas de cultos a forças anônimas e poderes indefinidos. Neste sentido, a justificativa de nossa abordagem indica para o fato da religião ter sido legitimadora de formas de poder ao longo dos tempos. Todavia, isso não anularia o seu potencial criador e nem o seu impulso para a ação coletiva. A hipótese retratada é que, em última análise, a religião ensina as pessoas a viver melhor e fornece para as sociedades o alicerce para a estabilidade nas relações sociais.

\section{O Cenário Religioso Brasileiro Contemporâneo}

Chegará um dia em que nossas sociedades conhecerão, novamente, horas de efervescência criadora, no decurso das quais surgirão novos ideais, aparecerão novas fórmulas que servirão, durante algum tempo, de guia para a humanidade. (DURKHEIM, 2000, p. 474). 
O mundo da permanência e do absoluto tende, nos dias atuais, a apresentar novas faces na direção de um movimento, ao mesmo tempo de fluxo e refluxo, de ruptura e restauração, de transformação e, em alguns casos, marcado pela incapacidade em equacionar questões contingenciais às identidades eclesiais e também acerca de categorias tradicionais para análise dos fenômenos religiosos (CASSIRER, 1994).

O que encontramos na origem e na base do pensamento religioso não são seres ou objetos determinados e distintos que possuem por si próprio o caráter sagrado, mas, sim, poderes indefinidos, formas anônimas, mais ou menos numerosas conforme as sociedades, às vezes, até reduzidas a unidade cuja impessoalidade, é perfeitamente comparável às forças físicas que têm suas manifestações perfeitamente estudadas pelas ciências da natureza (DURKHEIM, 2000, p. 203).

É inegável a emergência do indivíduo como suporte da vida social. Se para Durkheim "não há religião sem igreja", hoje, mais do que nunca, e em sentido profundo, "não poderia existir religião sem indivíduos religiosos". Não se trata, todavia, da "pessoa" com suas exigências de construção e procura autônoma da verdade, mas, das formas que revestem o "indivíduo" na atualidade através de suas experiências, de sua adesão a uma verdade construída e assumida por meio do exercício da razão e do cultivo da emoção, por vezes, partilhada.

Os conteúdos de fé outrora objetivados, dados como revelados e transmitidos pela tradição, são atualmente triados, selecionados, avaliados e, depois transformados pelas consciências individuais segundo sua autenticidade percebida e experimentada. A religião não se apresenta mais como um quadro geral de autoridade, regulado por um aparelho que distribui o verdadeiro, o justo e o proibido; ela é primeiramente e sobre tudo um dispositivo de crenças e de práticas que as pessoas devem "sentir" em suas próprias vidas (BOBINEAU; TANK-STORPER, 2011, 104).

É, pois, plausível e pertinente constatar que a vivência religiosa dos dias atuais é marcada por uma desinstitucionalização cada vez maior. As sólidas estruturas que fundavam e regulavam o universo das experiências religiosas, conferindo-lhes distinção, conteúdo e identidade, não se plenificam mais com tanto rigor e abrangência (VATTIMO, 2004). Esta realidade sugere a circulação, composição e múltiplas pertenças a 
atravessar os sentidos da pluralidade orientando o comportamento dos indivíduos.

A novidade da religião moderna não é o sincretismo - pois crenças de diferentes procedências sempre se misturam -, mas o caráter sincrético das identidades religiosas, a convivência de múltiplas pertenças. A destradicionalização generalizada das sociedades contemporâneas se expressa na crise das instituições religiosas e na liberdade do sujeito em relação aos complexos sistemas de construção das identidades tradicionais. $\mathrm{O}$ mal-estar das instituições pela fluidez e instabilidade de seus adeptos não significa um mal-estar do sujeito religioso moderno. Pelo contrário, a liberdade de escolha religiosa lhe é bem mais cômoda (BARREIRA, 2003, p. 462).

De acordo com o destacado pesquisador Faustino Teixeira, "não é tarefa simples entender a presença da religião ou do dinamismo religioso na contemporaneidade". Para ele, "há, de um lado, aqueles que defendem com vigor a força da secularização, chegando mesmo a falar no 'fim' ou na 'saída da religião'”. Por outro lado, "autores, como Peter Berger (2003), falam em ressurgência da religião, questionando as teses tradicionais que defendem a vigência de um mundo cada vez mais secularizado". Teixeira, baseado em Berger, afirma que o mundo continua bastante religioso, o que tem sido chamado também de retorno do religioso, aspecto que possui uma expressão também nos fundamentalismos. Este quadro torna indispensável o estudo das religiões na atualidade (TEIXEIRA, 2014, p. 34). Ademais, inconteste é a presença das religiões no espaço público.

O que ocorre é que as religiões estão aí, e também as espiritualidades laicas que não se encaixam no tradicional perfil religioso. São, sem dúvida, metamorfoses no âmbito da fé que traduzem uma forma de expressão religiosa diferente daquela rotineira. $\mathrm{O}$ avanço da modernidade não produziu, na verdade, uma menor presença da religião, mas outra forma de dinâmica religiosa (TEIXEIRA, 2014, p. 35).

Apesar dos fundamentalismos, Teixeira parte da noção de um "contexto religioso cada vez mais plural" que tem a ver com "o enfraquecimento dos exclusivismos religiosos, e uma compreensão mais fluida e aberta com respeito à verdade religiosa" (TEIXEIRA, 2014, p. 35). Afirmação que o autor corrobora com dados estatísticos do Pew Research Center de 2010: 
O cristianismo continua hegemônico, abarcando 31,5\% da população mundial, com cerca de 2,2 bilhões de adeptos. E dentre os cristãos, os católicos ocupam a primeira posição, respondendo pela metade desse contingente de adeptos (50\%), e na sequência, a tradição protestante, com a inclusão dos anglicanos, outras tradições evangélicas independentes e igrejas não denominacionais (37\%), bem como a Comunhão Ortodoxa da Grécia e da Rússia (12\%). O islamismo vem em seguida, envolvendo $23,2 \%$ da população geral, com cerca de 1,6 bilhões de adeptos, cuja grande maioria (entre 87 a 90\%) da tradição sunita. Não filiados vêm em terceiro lugar, abrangendo $16,3 \%$ da população global, em torno de 1,1 bilhões de adeptos. [...] Mas segundo um survey mais recente do mesmo centro de pesquisa americano, realizado em 2012, esses números cresceram, envolvendo agora $19,6 \%$ dos americanos adultos, dos quais 3,3\% são agnósticos e $2,4 \%$ ateus. O hinduísmo ocupa a quarta posição, cobrindo $15,0 \%$ da população mundial, com aproximadamente 1 bilhão de fiéis. Na sequência, aparecem o budismo (7,1\% - 488 milhões), as religiões étnicas ou regionais $(5,9 \%$ - 405 milhões), outras religiões $(0,8 \%-58$ milhões) 11 e judaísmo (0,2\% - 14 milhões) (TEIXEIRA, 2014, p. 35-36).

Os dados trazidos, efetivamente, corroboram com a tese de que o mundo continua significativamente religioso. É evidente que estas pesquisas podem deixar de notar alguns hibridismos, no entanto, eles também denotam questões pertinentes para a compreensão do cenário religioso no Brasil, como no quadro abaixo referente à distribuição das religiões no país:

\begin{tabular}{|c|c|c|c|c|}
\hline \multicolumn{5}{|c|}{ POPULAC̄̃̃ RESIDENTE, POR RELIGIÃO - BRASIL 1980 - 2010 (\%) } \\
\hline & 1980 & 1991 & 2000 & 2010 \\
\hline CATÓLICOSROMANOS & 89,0 & 83,3 & 73,6 & 64,6 \\
\hline EVANGÉLICOS & 6,6 & 9,0 & 15,4 & 22,2 \\
\hline ESPÍRITAS & 0,7 & 1,1 & 1,3 & 2,0 \\
\hline UMBANDA ECANDOMBLÉ & 0,6 & 0,4 & 0,3 & 0,3 \\
\hline OUTRASRELIGIOSIDADES & 1,5 & 1,4 & 1,8 & 2,9 \\
\hline SEMRELIIIÃOO & 1,6 & 4,8 & 7,4 & 8,0 \\
\hline
\end{tabular}

Fonte: IBGE, Censos 1980; 1991; 2000; 2010.

Figura 1: Quadro presente em: MENEZES, R. Religiões, número e disputas sociais. In: Comunicações do ISER, Rio de Janeiro, n.69, 2014, p. 61. 
De acordo com o censo de 2010, a partir da soma de católicos romanos e evangélicos, é notável o fato de que o Brasil conta com quase $87 \%$ de cristãos. Apenas $8 \%$ da população sem religião (o que não quer dizer que não sejam religiosos, indica apenas a não filiação a alguma instituição religiosa). Para Teixeira, "a retração do catolicismo não se reflete na diminuição do cristianismo, já que o crescimento dos evangélicos vem se acentuando a cada década". Apesar da diminuição de católicos, há um quadro de pluralização dentro do cristianismo (TEIXEIRA, 2014, p. 37).

Entre os evangélicos merece especial destaque o grupo dos pentecostais "que responde por mais de dois terços do total de evangélicos" (TEIXEIRA, 2014, p. 38). Entre os pentecostais, por sua vez, "registra-se a pujança da Assembleia de Deus (AD), responsável pela maior presença pentecostal no Brasil, envolvendo 12,3 milhões de adeptos". Uma característica marcante deste grupo é sua "penetração nos mais distantes e inacessíveis rincões", há uma significativa capacidade de capilaridade dessas igrejas. "E, a isso, soma-se a singular capacidade destas igrejas, e em particular da AD, de gerar laços de confiança, de fidelidade, de autoestima que facultam iniciativas de ajuda mútua na linha da transformação das condições de vida" (TEIXEIRA, 2014, p. 38). Sobre esta questão, comentam Albano e Baade:

A espiritualidade pentecostal é caracterizada pelo batismo no Espírito Santo, dons espirituais, participação leiga e pela evangelização. Trata-se de uma espiritualidade marcada pela experiência pessoal e pela emotividade. O batismo no Espírito Santo pode ser entendido como empoderamento da vida. Essa experiência pentecostal profana as formas convencionais de ministério cristão, devolvendo-o àqueles de quem havia sido tirado. Para o bem e para o mal, influenciou e transformou aspectos do cenário religioso brasileiro, afirmando a vida daqueles de quem o protagonismo cristão havia sido usurpado (ALBANO; BAADE, 2016, p. 110).

O quadro de empoderamento descrito pelos autores é, sem dúvida, um dos fatores que contribuem para o crescimento das Assembleias de Deus. Estas comunidades, mais recentemente, vêm crescendo também em formação teológica, na medida em que está produzindo uma primeira geração de pesquisadores no âmbito de uma teologia contextual e dialógica. Outro grupo, menor, mas que também requer atenção são 
os assim chamados sem religião. Teixeira (2014, p. 40) entende que eles "estão mesmo desencaixados de laços institucionais, situando-se melhor como peregrinos do sentido". Não podem ser compreendidos como a-religiosos.

Entre os tipos predominantes de sem religião, encontram-se aqueles que se desvincularam de uma religião tradicional e afirmam sua crença com base em rearranjos pessoais; aqueles que passaram por diversos trânsitos, mas que não se encontraram em nenhum deles; aqueles que mantêm uma espiritualidade leiga ou secular; aqueles que mantêm uma filiação fluida em razão da indisponibilidade de participação religiosa regular e aqueles que se definem como ateus ou agnósticos (TEIXEIRA, 2014, p. 40).

Neste contexto, diante da tese da incontestabilidade da presença das religiões na sociedade, "vale sublinhar que o grupo dos agnósticos ou ateus não é o mais expressivo dentre os declarantes [como sem religião], envolvendo respectivamente $124,4 \mathrm{mil}(0,07 \%)$ e $615 \mathrm{mil}$ (0,32\%) pessoas" (TEIXEIRA, 2014, p. 40).

Atenta o autor, acerca desse grupo, que "não é incorreto dizer que a declaração sem religião traduz um "estado de desfiliação religiosa"” (TEIXEIRA, 2014, p. 40). Contudo, cabe "complementar essa reflexão com um traço de dinamicidade, ou seja, sublinhar que esse estado pode ser passageiro, ou um estado de trânsito, onde as pessoas estão em 'redefinição' de sua inscrição identitária” (TEIXEIRA, 2014, p. 41).

A característica chave de todas as situações [...] quaisquer que sejam os detalhes de seu pano de fundo histórico, é que os antigos monopólios religiosos não podem mais contar com a submissão de suas populações. A submissão é voluntária e, assim, por definição, não é segura. Resulta daí que a tradição religiosa, que antigamente podia ser imposta pela autoridade, agora tem que ser colocada no mercado. Ela tem que ser "vendida" para uma clientela que não está mais obrigada a "comprar". A situação pluralista é, acima de tudo, uma situação de mercado (BERGER, 2003, p. 149).

Do ponto de vista da composição religiosa brasileira, tudo leva a crer que vivemos tempos de certa inflexão. Há uma diluição dos comportamentos tradicionais que exacerbaram a demografia religiosa no decorrer da história do país (ABUMANSSUR, 2014, p. 55-73). Se 
por um lado é possível vislumbrar uma maior liberdade religiosa nos termos de uma livre concorrência e as implicações deste fenômeno, sobretudo para a esfera pública, por outro, é inegável a retração numérica da matriz católica, protestante de ascendência luterana e umbandista. A demografia religiosa no Brasil evidencia uma capacidade de valorizar os processos de individualização da fé sem deixar de lado uma evidente "sacralização secular".

\section{Durkheim e as Perspectivas da Religião na Contemporaneidade}

Durkheim foi o precursor de um pensamento que buscava mostrar a riqueza e a complexidade de um propósito teórico dotado de inventividade científica no qual o ser humano estava profundamente implicado. Filho e neto de rabinos, mas sempre se apresentando como agnóstico, racionalista ou ateu, propunha um ideal coletivo onde a questão da religião era a peça maior. É nos seus escritos que ela se torna, progressivamente, a chave de sua problemática das interações sociais a ponto de suscitar a irritação de seus colaboradores (WILLAIME, 2012).

É na religião que Durkheim encontra a forma primeira desse espirito comum que faz a sociedade se manter reunida. Para ele, a sociedade não é apenas um agregado de indivíduos que ocupam um espaço dado em condições materiais determinadas. Ela é antes de tudo um conjunto de ideias, de crenças, de sentimentos de todos os tipos que se realizam por meio de indivíduos e, na primeira fila dessas ideias encontra-se o ideal moral, que é a sua principal razão de ser (SANCHIS, 2003).

Todas as crenças religiosas conhecidas, sejam elas simples ou complexas, apresentam um mesmo caráter comum: supõem uma classificação das coisas, reais ou ideais, que os homens representam, em duas classes ou em dois gêneros opostos, designados geralmente por dois termos distintos traduzidos, relativamente bem, pelas palavras profano e sagrado (DURKHEIM, 2000, p.68).

Estudar a religião é estudar as condições de formação nos termos de um ideal moral. É igualmente e, de forma inseparável, perguntar sobre o futuro da sociedade, quando esta realidade moral - como no 
caso da sociedade moderna - deixa de se expressar sob uma forma religiosa. É preciso descobrir, portanto, as forças que os indivíduos aprenderam a representar para si mesmos sob a forma de alegorias religiosas (MARTELLI, 1995). É preciso destaca-las de seus símbolos e apresenta-las em sua particularidade racional. Estudar a religião é, sobretudo, remontar às fontes da ligação social para melhor pensar a refundação possível desta ligação em uma sociedade laicizada.

O aspecto característico do fenômeno religioso é o fato de que ele pressupõe sempre uma divisão do universo conhecido e cognoscível em dois gêneros que englobam tudo aquilo que existe, mas que radicalmente se excluem. As crenças religiosas são representações que exprimem a natureza das coisas sagradas e as relações que têm entre si e com as coisas profanas. Os ritos são, afinal, regras de conduta que prescrevem o modo como o homem se deve comportar perante as coisas sagradas (DURKHEIM, 2000, p. 24).

O propósito não é dizer o que é a religião, mas descobrir um conjunto de fenômenos que juntos explicitem por que eles apresentam características comuns (ORTIZ, 2002, p. 123-148). Durkheim esboça a sua teoria com base em uma crítica das definições da religião fundadas sobre a noção de "sobrenatural" ou sobre a categoria de "divindade" observando que algumas religiões não fazem referência alguma a este aspecto.

Rejeita-se de forma expressa a ideia de definir os fatos religiosos a partir de "praticas relativas a coisas sagradas", ou seja, a partir do culto, por exemplo. Para ele esta operação mais seria uma espécie de substituição de um termo (religião) por outro (sagrado). Esta substituição não traria, em última análise, nenhuma clareza, nenhum auxílio ou princípio para explicitar a realidade (BATAILLE, 1993). As crenças que suscitam uma obrigatoriedade são formalizadas sob a forma de mitos e de dogmas que se expressam em cerimônias e rituais (HALBWACHS, 1990). É elementar e primordial, portanto, explicar a origem social deste "respeito" que se apodera dos crentes e que os empenha a não duvidar daquilo que creem.

A função da religião é fazer-nos agir, é auxiliar-nos a viver. O fiel que se comunicou com Deus não é apenas um homem que vê novas verdades 
que o descrente ignora; ele é um homem que pode mais. Ele sente em si mais força seja para suportar as dificuldades da existência, seja para vencê-las. Ele está como que elevado acima de sua condição de homem. Acredita ser salvo do mal sob qualquer forma. O primeiro artigo de toda a fé é a crença na salvação pela fé (DURKHEIM, 2000, p. 30).

A hipótese para responder que as forças diante das quais o crente se inclina não seriam simples energias físicas, tais como se apresentam aos sentidos e à imaginação, mas, forças sociais. Elas seriam o produto direto dos sentimentos coletivos que foram levados a tomar um revestimento material (CAMPBELL; MOYERS, 2004). Quais são estes sentimentos? Quais causas sociais? O que determinou que as coisas se exprimissem de tal maneira? À quais fins corresponde a organização? Estas são questões que deveriam ser tratadas pela ciência que estuda as religiões.

Durkheim oferece uma espécie de "resumo" de suas perspectivas acerca da religião. Ele define que as concepções religiosas enquanto objeto de análise deveriam ser vistas não a partir daquilo que tem de excepcional ou anormal, mas daquilo que teriam de constante e regular. Para abordar de forma correta a religião dos "primitivos" ele sugere o esforço para restituir o sentido vivido destas crenças para os próprios interessados.

A religião transborda a ideia de deuses e de espíritos e, por conseguinte, não poderia ser definida com base apenas nesta perspectiva. Para enfrentar o problema da definição da religião seria preciso primeiro afastar o projeto de aprender a natureza da religião em seu conjunto, como se ela formasse uma espécie de "entidade invisível" (LUCKMANN, 2014). A religião é um todo. Um sistema complexo de mitos, de dogmas, de ritos e de cerimônias. Para compreendê-la de forma profunda seria preciso decompor este conjunto e caracterizar os fenômenos elementares dos quais toda a religião resulta (EAGLETON, 2016). A distinção entre o sagrado e o profano estaria, de certo modo, no âmago de toda a religião:

Todas as crenças religiosas conhecidas, sejam elas simples ou complexas, apresentam caráter comum: elas supõem uma classificação das coisas, reais ou ideais, que os homens representam em duas classes, em dois gêneros opostos, designados socialmente por dois termos distintos que traduzem muito bem os termos sagrado e profano. É essa separação radical que, 
enquanto tal, é importante. O círculo dos objetos sagrados pode ele próprio variar consideravelmente conforme as religiões e o caráter sagrado que lhes é reconhecido, mas, não significa, necessariamente, que se lhes atribua um valor eminente ou de uma superioridade particular. Há objetos sagrados com os quais o homem se sente inteiramente à vontade. Acontece que batemos no fetiche quando não estamos contentes e nos reconciliamos com ele caso se mostre mais dócil (DURKHEIM, 2000, p. 52).

Se não houver uma espécie de hierarquia, a heterogeneidade do sagrado e do profano não seria menos absoluta. A crítica, portanto, é de que, historicamente, o sagrado e o profano sempre foram definidos como gêneros separados, como dois mundos entre os quais não havia nada em comum. Esta separação não significa que não haja uma passagem entre um e outro, mas que esta passagem, quando acontece, põe em evidência a dualidade entre dois reinos. Há, portanto, um constante embate no qual acontece uma busca de subordinação, imposição e múltiplas precauções e metamorfoses.

A cultura muda. A religião muda. No mundo contemporâneo, em seu lado ocidental, se a religião não acompanha a cultura, fica para trás. Ainda tem fôlego para interferir na cultura e na sociedade, sobretudo na normatização de aspectos da intimidade do indivíduo - especialmente pelo fato de ser religião -, mas seu sucesso depende de sua capacidade de mostrar ao fiel potencial o que ela pode fazer por ele. Dotando-o, sobretudo, dos meios simbólicos para que a vida possa fazer algum sentido e se tornar, subjetiva ou objetivamente, mais fácil de ser vivida, sem que se tenha de abandonar o que de bom este mundo oferece (PRANDI, 2008, p. 170).

Para Durkheim haveria uma consistência nos fenômenos sociais de modo que estes contribuem para modelar a vida e os costumes. Implicam profundamente os indivíduos e os grupos humanos, oferecendo orientação e segurança para suas ações. Haveria uma continuidade entre as crenças das sociedades tradicionais e as crenças coletivas que fazem viver os seres humanos da modernidade mesmo que a ciência tenha expulsado a maioria das cosmologias que detinham a explicação do mundo para fora das fronteiras da "racionalidade".

No plano empírico, mesmo que formas religiosas tradicionais desapareçam, os grupos humanos serão sempre capazes de encontrar novos símbolos de solidariedade, apropriados ao novo grau de desenvolvimento 
da sociedade. No plano teórico, depreende-se que a religião terá sempre uma função social a cumprir, o que garante a perenidade, ainda que de formas históricas as mais variadas (ROSADO-NUNES, 2007, p.107).

Todo grupo humano é levado a forjar, a partir das experiências do seu cotidiano, hipóteses explicativas que permitam dar um sentido às situações vividas e partilhar essas significações (ZIZEK, 2012). Mesmo que nas sociedades modernas as exigências da razão dedutiva e da verificação experimental estejam longe de serem definitivas, multiplicam-se formas "irracionais" que permitem aos seres humanos perceber aquilo que fazem, sentem e buscam (COLLINS, 2009). Durkheim tenta descobrir a "verdade" da religião através da observação, do aprendizado "in loco" em termos de diversidade e multiplicidade dos fenômenos.

O que encontramos na origem e na base do pensamento religioso não são objetos ou seres determinados ou distintos, que possuam por si mesmos um caráter sagrado; são, ao contrario, poderes indefinidos, forças anônimas, mais ou menos numerosas conforme as sociedades, por vezes até reconduzidas à unidade e cuja impessoalidade é estreitamente comparável à das forças físicas, cujas manifestações são estudadas pelas ciências da natureza (DURKHEIM, 2000, p. 285-286).

A partir do critério durkheimniano torna-se possível supor, descobrir e delimitar possíveis "retornos", "renovações" e "ressurgências" contemporâneas de uma "sacralidade" constituída como dimensão antropológica universal. É uma possibilidade para debater a modernidade religiosa em tempos onde ainda há uma definição, por vezes, muito restritiva da religião em termos de conteúdos (sobrenatural) e em termos de uma definição funcional (interesses).

O que é especificamente "moderno" não é o fato de os homens ora se aterem ora abandonarem a religião, mas é o fato de que a pretensão que a religião tem de reger a sociedade inteira e governar toda a vida de cada indivíduo foi-se tornando ilegítimo, mesmo aos olhos dos crentes mais convictos e mais fiéis. Nas sociedades modernas, a crença e a participação religiosa são 'assuntos de opção pessoal': são assuntos particulares que dependem da consciência individual e que nenhuma instituição religiosa ou política podem impor a quem quer que seja (HERVIEU-LÉGER, 2008, p. 34). 
Durkheim soube antecipar os aspectos advindos do movimento de secularização que faz escapar a maioria das atividades e as experiências humanas da influência reguladora das instituições religiosas. Isso não significa que as instituições religiosas não sejam capazes de gerar experiências do sagrado, mas elas não podem mais, prender o monopólio de tal experiência coletiva, que se manifesta em todas as sociedades modernas, de formas dispersas e localizadas em todas as atividades da vida social (TOURAINE, 1998).

Ao conceber a sociedade a partir de verdades e princípios, Durkheim entabula possibilidades em alusão ao pragmatismo. Este seria um elemento intrínseco às interpretações sociais, a partir da própria percepção dos sujeitos diante das representações coletivas existentes. Trata-se de uma expressão da realidade emanada de significados de sujeitos que devem lidar com seus sentimentos não por interpretações causais ou utilitárias, mas necessárias e de acordo com uma representação coletiva.

É certo que os seres humanos possuem a capacidade para criar novas moralidades que serviriam de substrato ideacional para a vida social. É, pois, na religião que ocorre, de acordo com Durkheim, a forma primeira do espírito comum que faz a sociedade se manter reunida. Para ele, a sociedade é antes de tudo um conjunto de ideias, de crenças, de sentimentos de todos os tipos que se realizam por meio de indivíduos tornando possível supor, descobrir e delimitar "retornos", "renovações" e "ressurgências" de uma "sacralidade" constituída como dimensão antropológica universal.

\section{Considerações Finais}

Entre as questões suscitadas, segundo a perspectiva delineada por Durkheim, é preciso destacar que o sagrado encontra-se diretamente vinculado às sociedades. As crenças religiosas seriam representações coletivas. Relevante nesta abordagem, portanto, é a quebra da visão dominante no final do século XIX que atribuía o pensamento mítico e religioso, e por extensão o pensamento mágico, ao campo do primitivismo arcaico a ser substituído pela verdade científica. 
Se a religião era uma construção social, então deveria acompanhar as características de cada sociedade. A universalidade da religião ocorre pelas forças que ela representa e que estão presentes nas formações sociais. A percepção acerca da existência de forças elementares que estão presentes em todas as sociedades, das mais simples às mais complexas, ganha contornos próprios. Se a sociedade evolui e se transforma, o mesmo deveria acontecer com a dimensão religiosa.

A noção de religião é compreendida enquanto congregação de fiéis reunidos em torno de uma instituição. Porém, para além dos grupos organizados, há novas expressões e manifestações. Por isso, a autonomia dos sujeitos também indica para uma quebra de referências antes direcionadas às instituições. Agora, ocorre um condicionamento pactuado por questões internas, mais subjetivas. Há, portanto, uma crescente valorização da consciência interior, das experiências corporais e da autonomia. A religião institucionalizada tende a não ser mais tão valorizada, embora seus princípios continuem sendo vistos como fontes de uma intencionalidade peculiar, de sentido ou verdade.

Os valores a partir de fontes externas ao indivíduo começam a ser substituídos por valores do próprio sujeito, baseados na experiência. Trata-se de uma mudança que é ampliada para outros setores da convivência humana e social, na família e no âmbito educacional, por exemplo. Antigas autoridades são questionadas, mas não suprimidas. Elas tendem a ser seguidas na medida em que enalteçam a livre escolha dos sujeitos. Não se trata, portanto, de negar a religião, mas de sublinhar uma opção protagonizada em nível de sujeitos individuais.

É importante salientar a atualidade do pensamento de Durkheim na perspectiva de um amplo processo de mudanças. Isso significa que as diferentes expressões religiosas exacerbam múltiplas transformações no interior das principais matrizes religiosas, bem como na maneira como os seus adeptos buscam viver a religiosidade sem submetê-la aos padrões contingenciados pelas autoridades eclesiásticas. Trata-se da religião, assim como preconizada por Durkheim, acompanhando as mudanças do meio social e sendo um reflexo da própria sociedade. 


\section{Referências Bibliográficas}

ABUMANSSUR, Edin Sued. A coisa. In: BITUN, Ricardo; SOUZA, Rodrigo Franklin de. (Org.). Estudos sobre Durkheim e a Religião. Santo André: Academia Cristã, 2014, p. 55-73.

ALBANO, Fernando; BAADE, Joel. A espiritualidade pentecostal como presença transformadora. Estudos Teológicos, São Leopoldo, v. 56, n. 1, jan./ jun., 2016, p. 110-121.

BARREIRA, Dario Paulo Rivera. Fragmentação do sagrado e crise das tradições na pós-modernidade. In: TRASFERETTI, José (Org.). Teologia na Pós-modernidade. São Paulo: Paulinas, 2003, p. 437-464.

BATAILLE, Georges. Teoria da Religião. São Paulo: Ática, 1993.

BERGER, Peter. O dossel sagrado. Elementos para uma teoria sociológica da religião. São Paulo: Paulus, 2003.

BOBINEAU, Olivier; TANK-STORPER, Sebastien. Sociologia das Religiões. São Paulo: Loyola, 2011.

CAMPBELL, Joseph \& MOYERS, Bill. O Poder do Mito. São Paulo: Palas Athenas, 2004.

CASSIRER, Ernst. Ensaio sobre o Homem: introdução a uma filosofia da cultura humana. Martins Fontes: São Paulo, 1994.

COLLINS, Randall. Quatro tradições sociológicas. Rio de Janeiro: Vozes, 2009 .

DURKHEIM, Émile. As Formas Elementares da Vida Religiosa. São Paulo: Martins Fontes, 2000.

DURKHEIM, Émile. Pragmatismo e Sociologia. Florianópolis: Tubarão: Unisul, 2004.

DURKHEIM, Émile. As Regras do Método Sociológico. São Paulo: Martins Fontes, 2007.

DURKHEIM, Émile. Da Divisão do Trabalho Social. São Paulo: Martins Fontes, 2008.

EAGleton, Terry. A Morte de Deus na Cultura. Rio de Janeiro: Record, 2016.

GIDDENS, Anthony. Durkheim. London: Fontana Press, 1986.

HALBWACHS, Maurice. A Memória Coletiva. São Paulo: Vértice, 1990. 
LUCKMANN, Thomas. A Religião Invisível. São Paulo: Loyola, 2014.

MARTELLI, Stefano. A religião na sociedade pós-moderna: entre secularização e dessecularização. São Paulo: Paulinas, 1995.

MENEZES, Renata. Religiões, número e disputas sociais. Comunicações do ISER, Rio de Janeiro, n.69, 2014, p. 60-70.

ORTIZ, Renato. Durkheim: um percurso sociológico. In: Ciências Sociais e Trabalho Intelectual. São Paulo: Olho dágua, 2002, p. 123-148.

PRANDI, Reginaldo. Converter indivíduos, mudar culturas. Tempo Social. Vol. 20. Ano 2. São Paulo, 2008, p. 155-172.

ROSADO-NUNES, Maria. J. F. A sociologia da religião. In: USARSKI, Frank (org.). O espectro disciplina da Ciência da Religião. São Paulo: Paulinas, 2007, p. $97-119$.

SANCHIS, Pierre. A contribuição de Émile Durkheim. In: TEIXEIRA, Faustino. (Org.). Sociologia da religião: enfoques teóricos. Petrópolis: Vozes, 2003.

TEIXEIRA, Faustino. Campo religioso em transformação. In: Comunicações do ISER, Rio de Janeiro, n.69, 2014, p. 34-45.

TOURAINE, Alain. Igualdade e diversidade: o sujeito democrático. São Paulo: Edusc, 1998.

WILLAIME, Jean-Paul. Sociologia das religiões. São Paulo: Ed. UNESP, 2012.

VATTIMO, Gianni. Depois da Cristandade: por um cristianismo não religioso. Rio de Janeiro: Record, 2004.

ZIZEK, Slavoj. O amor impiedoso (ou: Sobre a crença). Belo Horizonte: Autêntica Editora, 2012. 